\title{
RANCANG BANGUN OIL SYSTEM UNTUK TURBOCHARGER GAS TURBINE ENGINE DENGAN INDUCER DIAMETER 1,75 INCH
}

\author{
Noval Dwi Kurnianto ${ }^{(1)}$, Wira Gauthama ${ }^{(2)}$, Zulham Hidayat ${ }^{(3)}$ \\ ${ }_{1,2,3}$ Politeknik Penerbangan Indonesia Curug \\ e-mail: ${ }^{1}$ vallekurnianto04@gmail.com, ${ }^{2}$ wira.gauthama@ppicurug.ac.id \\ ${ }^{3}$ zulham.hidayat@ppicurug.ac.id
}

\begin{abstract}
Abstrak: Rancang bangun mesin turbin gas dimulai dengan mengidentifikasi beberapa komponen yang dibutuhkan dalam membangun sebuah mesin turbin gas. Turbocharger yang terdiri dari kompresor dan turbin sebagai penyusun utama komponen ini diambil untuk dijadikan Kompresor dan turbin mesin turbin gas yang juga merupakan unsur utama dalam sebuah mesin turbin gas. Agar sebuah mesin turbin gas dapat beroperasi maka perlu dirancang beberapa system pendukung seperti Oil System, Fuel System, Ignation System, Combustion Chamber dan beberapa system yang lain. Pada perancangan ini, penulis mendapat bagian dalam perancangan Sistem pelumas (Oil System) dimana tantangan yang dihadapi adalah mendapatkan jenis oil yang tepat untuk mesin turbin gas yang akan dibangun. Adapun rumusan masalah dalam perancangan system pelumas ini antara lain bagaimana menentukan viskositas pelumas yang digunakan, menghitung critical pressure bearing, menghitung jumlah pelumas yang digunakan, menghitung head pompa dan menghitung kapasitas reservoir yang digunakan. Output akhir yang dihasilkan dari perancangan ini adalah suplai oli yang mampu untuk melumasi shaft bearing pada turbocharger sehingga tidak terjadi overheating yang menyebabkan keausan serta metal to metal contact. Dari hasil perhitungan, didapatkan tekanan oli sebesar 37 psi yang diperlukan untuk melumasi shaft bearing pada turbocharger. Dan dihasilkan pembakaran yang continuous.
\end{abstract}

Kata Kunci: gas turbine engine, oil system, turbocharger.

Abstract: $\quad$ Manufacturing of gas turbine engine was started by identification of some components and systems involve in building the gas turbine engine. A turbocharger which consist of turbine and compressor as the main part was taken to make a turbine and compressor in Gas turbine engine. Those component is also the essential part of the machine. To operate the gas turbine engine, it is important to design some system such as Oil system, fuel System, Ignition System, combustion chamber, and others. In this

http://journal.ppicurug.ac.id/index.php/jurnal-langit-biru 
Rancang Bangun Oil System untuk Turbocharger Gas Turbine Engine Dengan Inducer Diameter 1,75 Inch

design project the writer obtains the task to design the oil system that fit and suitable for this type of gas turbine engine. Any issue related to this design such as how to decide the viscosity of the oil, calculate critical pressure of bearing, calculate mass of the oil fluid, head pressure of the pump and reservoir capacity. The final outcome of this design is correct supply of the oil flow which is used to lubricate shaft bearing in gas turbine engine. This system also prevent the machine from over heating that can degrade components of the engine due to metal to metal contact. From the final calculation found 37 psi oil pressure is needed to lubricate shaft bearing and can maintain the continuous operation of the engine.

Keyword: $\quad$ gas turbine engine, oil system, turbocharger.

\section{PENDAHULUAN}

\section{Latar Belakang}

Turbin gas adalah sebuah mesin panas pembakaran dalam, proses kerjanya seperti motor bakar, yaitu udara atmosfer dihisap masuk kompresor dan dikompresi, kemudian udara dimampatkan masuk ruang bakar dan dipakai untuk proses pembakaran, sehingga diperoleh suatu energi panas yang besar, energi panas tersebut diekspansikan pada turbin dan menghasilkan energi mekanik pada poros, sisa gas pembakaran yang keluar turbin menjadi energi dorong.

Daya keluaran dari turbin dipergunakan untuk menggerakan kompresor dengan menghubungkanya secara langsung. Keluaran daya bersih dari pembangkit daya turbin adalah daya keluaran turbin dikurangi daya yang dipergunakan untuk menggerakan kompresor. Prinsip dasar dari penerapan gas turbin ini menggunakan teori brayton.

Prinsip kerja turbocharger memanfaatkan tekanan yang dihasilkan dari exhaust pada piston engine sehingga memutar turbine yang akan memutar komporesor. Putaran dari kompresor dimanfaatkan untuk menyuplai udara yang melalui intake manifold untuk pembakaran pada piston engine. Penulis bermaksud merancang gas turbine engine dengan memanfaatkan sistem kerja turbocharger dan mengubah saluran dari piston engine menjadi combustion chamber dalam bentuk annular. Untuk menjaga agar shaft bearing pada turbocharger gas turbine engine dapat menahan panas yang dihasilkan dari putaran yang tinggi, dibutuhkan sistem pendinginan yang baik agar turbocharger gas turbine engine tersebut tidak overheating. Oleh karena itu, berdasarkan uraian tersebut yang telah dijelaskan, penulis akan mengangkat judul Rancang Bangun Oil System Untuk Turbocharger Gas Turbine Engine Dengan Inducer Diameter 1,75 Inch

\section{Identifikasi Masalah}

1. Bagaimanakah desain perancangan turbocharger gas turbine engine?

2. Bagaimanakah desain perancangan combustion chamber turbocharger gas turbine engine? 
3. Bagaimanakah desain perancangan oil system turbocharger gas turbine engine?

4. Bagaimanakah desain perancangan sistem bahan bakar pada gas turbine menggunakan turbo charger?

5. Bagaimanakah desain perancangan ignition system turbo charger gas turbine engine?

\section{Pembatasan Masalah}

Dari latar belakang dan identifikasi masalah yang telah dipaparkan di atas, maka penulis membatasi masalah bagaimana merancang oil system turbocharger gas turbine engine.

\section{Perumusan Masalah}

Dari pembatasan masalah diatas maka di rumuskan masalah tersebut menjadi sebagai berikut

1. Bagaimana menentukan kebutuhan oli pada system.

2. Komponen apa saja yang dibutuhkan dalam membangun Oil System

\section{Maksud dn Tujuan}

Maksud dan tujuan dari penulisan ini yaitu untuk merancang dan membuat oil system untuk turbocharger gas turbine engine dengan inducer diameter 1,75 inch sehingga Mesin dapat beroperasi dengan normal

\section{METODOLOGI PERANCANGAN Desain Perancangan \\ Kondisi saat ini}

Turbocharger ZAGE TD06SL220G merupakan suatu alat yang digunakan pada piston engine untuk meningkatkan performa dari mesin tersebut. Dengan memanfaatkan udara dari gas buang, udara gas buang tersebut masuk ke dalam turbine sehingga membuat turbine dari turbocharger berputar dan menyalurkan putaran tersebut untuk memutar compressor dan menghisap udara dari luar untuk masuk ke dalam ruang bakar. Udara dalam compressor dimampatkan dan disalurkan ke dalam ruang pembakaran sehingga dihasilkan tenaga yang besar

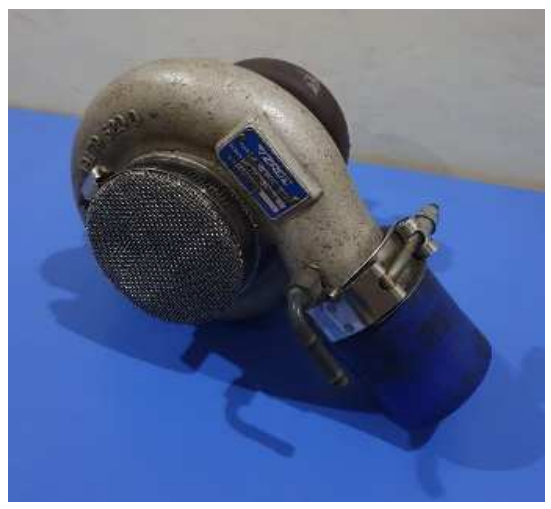

Gambar 1. Turbocharger ZAGE TD06SL2-20G

\section{Kondisi yang diinginkan}

Dengan kondisi sebelumnya, akan dirancang beberapa sistem agar dapat terbentuk menjadi sebuah jet engine sederhana dengan menggunakan turbocharger sebagai pengganti dari compressor dan turbine. Beberapa sistem tersebut diantaranya adalah oil system, fuel system, combustion system dan ignition system. Pada perancangan oil system pada turbocharger gas turbine engine, penulis menggunakan tipe oli SAE 20W-50, karena tipe oli SAE 20W-50 mampu memberikan perlindungan terbaik pada kondisi panas di mana suhu oli dapat melebihi $100^{\circ} \mathrm{C}$. Karena pada rancangan turbocharger gas turbine engine ini, engine RPM mencapai 77000, sehingga dibutuhkan viskositas yang kental untuk menjaga agar oil film yang terbentuk tetap mampu menahan shaft 
Rancang Bangun Oil System untuk Turbocharger Gas Turbine Engine Dengan Inducer Diameter 1,75 Inch

turbocharger, karena semakin tinggi putaran pada bearing akan semakin tinggi temperatur yang dihasilkan.. schematic diagram yang penulis rancang untuk sistem pelumasan adalah sebagai berikut :

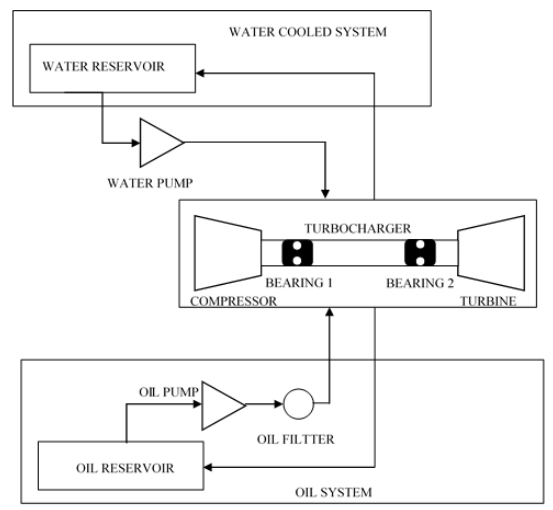

\section{Kriteria Perancangan}

Rancangan alat ini didesain dengan kriteria yang sesuai fungsi dan kegunaanya. Kriteria yang akan dijelaskan kelak akan dibandingkan dengan hasil uji coba dan hasil perhitungan apakah terdapat kesuaian, kriteria yang akan dijelaskan sebagai berikut :

1. Reservoir

Kriteria dari reservoir, mampu menampung oli yang digunakan untuk mengalirkan oli pada sistem.

2. Oil Pump

Kriteria dari oil pump, mampu mengalirkan oli sesuai dengan tekanan oli yang dibutuhkan oleh sistem.

3. Oil Filter

Kriteria Inline filter unit, mampu menyaring dan menghasilkan oli yang bersih untuk disalurkan pada sistem.

4. Water Cooling System
Kriteria Water cooling system, mampu mendinginkan center housing dari turbocharger agar tidak terjadi overheat.

5. Pressure Gauge

Pressure gauge berfungsi sebagai instrumen untuk mengetahui besar tekanan oli yang mengalir pada sistem.

6. Flexible Hose

Kriteria flexible hose, mampu menahan tekanan oli yang mengalir pada hose.

\section{Penggunaan Rancangan}

Setelah seluruh kriteria dibuat, tujuan dari perancangan oil system untuk turbocharger gas turbine engine adalah untuk menyediakan pelumasan yang cukup pada bearing dan shaft. .

\section{PEMBAHASAN}

\section{Gambaran Umum Perancangan}

Pada rancangan oil system untuk turbocharger gas turbine engine, oli akan dialirkan secara continous dengan komponen yang digunakan terdiri dari reservoir dengan kapasitas 4 liter, DC oil pump, oil filter, valve, pressure gauge, selang dengan ukuran 0,5 dan 0,25 inci serta water pump dan selang air untuk water coling system.

Rancangan oil system untuk turbocharger gas turbine engine, dimulai dengan mengalirkan oli dari reservoir oleh DC oil pump. Setelah oli memiliki tekanan oli akan melewati oil filter untuk menghasilkan aliran oli bertekanan yang bersih. Setelah itu oli akan masuk pada turbocharger shaft yang berfungsi untuk menjaga keausan pada bearing dan shaft serta untuk menjaga agar engine tidak overheat. 
Setelah itu oli akan kembali ke reservoir dengan memanfaatkan gravitasi.

Setelah melewati shaft pada turbocharger oli akan mengalami kenaikan suhu akibat gesekan dari shaft dan bearing. Water colling system digunakan untuk menjaga agar temperatur oli tidak terlalu panas. Sistem ini menggunakan air sebagai media pendingin pada oli, di mana air akan dipompa dan dialirkan melewati port pada turbocharger.

\section{Tahapan Perancangan}

1. Menentukan Viskositas Pelumas

$$
\tau=\frac{F}{A}
$$

a. Menghitung Gaya $(F)$

$$
\begin{aligned}
F & =\frac{(m \times g)}{n_{\text {bearing }}} \\
& =\frac{0,9 \times 9,8}{2} \\
& =4,41 \mathrm{~N}
\end{aligned}
$$

b. Menghitung Luas Area $(A)$

$$
\begin{aligned}
A & =l \times d \\
& =\left(9,41 \times 10^{-3}\right) \times(8,98 \\
& \left.\quad \times 10^{-3}\right) \\
& =8,45 \times 10^{-5} \mathrm{~m}^{2}
\end{aligned}
$$

c. Menghitung Shear Stress $(\tau)$

$$
\begin{aligned}
\tau & =\frac{F}{A} \\
& =\frac{4,41}{8,45 \times 10^{-5}}\left(\mathrm{~N} / \mathrm{m}^{2}\right) \\
& =52189,35 \mathrm{~N} / \mathrm{m}^{2}
\end{aligned}
$$

d. Menghitung

Clearance (c)

$$
\begin{aligned}
c & =D-d \\
& =9-8,980\left(10^{-3}\right) \\
& =0,020 \mathrm{~mm} \\
& =2 \times 10^{-5} \mathrm{~m}
\end{aligned}
$$

e. Menghitung Oil Film Thickness $\left(h_{0}\right)$

$$
\begin{aligned}
h_{0} & =\frac{c}{4} \\
& =\frac{2 \times 10^{-5}}{4} \\
& =5 \times 10^{-6} \mathrm{~m}
\end{aligned}
$$

f. Menghitung kecepatan bearing

( v )

$$
\begin{aligned}
v & =\pi d \times N \\
& =\frac{\pi \times\left(9 \times 10^{-3}\right) \times 77000}{60} \\
& =36,28 \mathrm{~m} / \mathrm{s}
\end{aligned}
$$

g. Menghitung absolute viscosity ( Z )

$$
\begin{aligned}
Z & =\tau \times \frac{h}{v} \\
& =52189,35 \times \frac{5 \times 10^{-6}}{36,28} \\
& =0,007 \mathrm{~kg} / \mathrm{ms}
\end{aligned}
$$

Absolute viscosity sebesar 0,007 $\mathrm{kg} / \mathrm{ms}$ pada suhu $90^{\circ} \mathrm{C}$

2. Menghitung Critical Pressure pada Journal Bearing

$$
\begin{aligned}
& p=\frac{Z N}{4.75 \times 10^{6}}\left(\frac{d}{c}\right)^{2}\left(\frac{l}{d+l}\right) \\
& =\frac{0,007 \times 77.000}{4,75 \times 10^{6}}\left(\frac{8,980}{0,020}\right)^{2}\left(\frac{9,41}{8,980+9,41}\right) \\
& =11,7 \mathrm{~N} / \mathrm{mm}^{2}
\end{aligned}
$$

3. Menghitung Coeficient of Friction

$$
\begin{aligned}
\mu & =\frac{33}{10^{8}}\left(\frac{Z N}{p}\right)\left(\frac{d}{c}\right)+k \\
& =\frac{33}{10^{8}}\left(\frac{0,007 \times 77000}{11,7}\right)\left(\frac{8,980}{0,020}\right) \\
& =0,008
\end{aligned}
$$

4. Menghitung Heat Generated in a Journal Bearing

$$
\begin{aligned}
\mathcal{Q}_{\mathrm{g}} & =\mu \times W \times v \\
& =\mu \times p(l \times d) \times v
\end{aligned}
$$


Rancang Bangun Oil System untuk Turbocharger Gas Turbine Engine Dengan Inducer Diameter 1,75 Inch

$$
\begin{aligned}
& =0,008 \times 11,7(9,41 \times 8.980) \\
& \times 36,28 \\
& =286,79 \mathrm{Watt}
\end{aligned}
$$

5. Menghitung Heat Dissipated by the Bearing

$$
\begin{aligned}
\mathcal{Q}_{d}= & C \times A\left(t_{b}-t_{a}\right) \\
\left(t_{b}-t_{a}\right)= & \frac{1}{2}\left(t_{0}-t_{a}\right) \\
= & \frac{1}{2}(90-22,5) \\
= & 33.75^{\circ} \mathrm{C} \\
\mathcal{Q}_{d}= & C \times A\left(t_{b}-t_{a}\right) \\
= & 945 \\
& \quad \times(8,45 \\
& \left.\quad \times 10^{-5}\right)(33,75) \\
= & 2,7 \text { Watt }
\end{aligned}
$$

6. Menghitung Jumlah Oli yang Dibutuhkan

Heat Taken by Oil

$$
\begin{gathered}
\quad=\text { Heat Generated } \\
- \text { Heat Dissipated } \\
\mathcal{Q}_{t}=\mathcal{Q}_{g}-\mathcal{Q}_{d} \\
=286,79-2,7 \\
=284,09 \mathrm{Watt} \\
\mathcal{Q}_{t}=m S t \\
284,09=m \times 1970 \times 20 \\
m=\frac{284,09}{1970 \times 20} \\
=0,0075 \mathrm{~kg} / \mathrm{s} \\
=0,45 \mathrm{~kg} / \mathrm{menit} \\
m=\rho \times V \\
V=\frac{m}{\rho}=\frac{0,45}{0,902} \\
Q=0,5 \mathrm{liter} / \text { menit }
\end{gathered}
$$

7. Menentukan Head Pompa

a. Menghitung Kecepatan Aliran

Oli

$$
\begin{aligned}
& Q=A v \\
& v=\frac{\mathrm{Q}}{A}
\end{aligned}
$$

$$
\begin{aligned}
& =\frac{8,33 \times 10^{-5}}{\frac{1}{4} \pi\left(6 \times 10^{-3}\right)^{2}} \\
& =2,94 \mathrm{~m} / \mathrm{s}
\end{aligned}
$$

b. Menentukan Diameter Selang

Diketahui :

$$
\begin{aligned}
Q & =0,5 \mathrm{liter} / \text { menit } \\
& =0,13 \mathrm{gpm} \\
v & =2,94 \mathrm{~m} / \mathrm{s} \\
& =9,64 \mathrm{ft} / \mathrm{s}
\end{aligned}
$$

c. Luas Area Selang :

$$
\begin{aligned}
d & =\sqrt{\frac{Q \times 0,4081}{v}} \\
& =\sqrt{\frac{0,13 \times 0,4081}{9,64}} \\
& =0,18 \mathrm{in} \\
& =4,7 \mathrm{~mm}
\end{aligned}
$$

d. Panjang selang

$$
\sqrt{0,8^{2}+0,6^{2}}=1 \mathrm{~m}
$$

8. Menghitung Daya Pompa

a. Menghitung head loss pada komponen

Diketahui :

$$
\begin{aligned}
Q & =0,5 \text { liter } / \text { menit } \\
Q & =8,33 \times 10^{-5} \mathrm{~m}^{3} / \mathrm{s} \\
d & =6,35 \times 10^{-3} \mathrm{~m} \\
v & =3,43 \mathrm{~m} / \mathrm{s}
\end{aligned}
$$

b. Bilangan Reynold

$R_{E}=\frac{v d}{V I}$

Diketahui :

$V I=101 \times 10^{-6} \mathrm{~m}^{2} / \mathrm{s}$

Besar Bilangan Reynold aliran oli adalah :

$R_{E}=\frac{v d}{V I}$ 


$$
\begin{aligned}
& =\frac{(3,43)\left(6,35 \times 10^{-3}\right)}{101 \times 10^{-6}} \\
& =215,6
\end{aligned}
$$

c. Faktor Gesekan

Dari hasil perhitungan, diperoleh nilai Bilangan Reynold kurang dari 2300, dari persamaan (22), didapat :

$f=64 / R_{E}$

Besar faktor gesekan adalah :

$$
\begin{aligned}
& f_{1}=64 / R_{E} \\
& f_{1}=64 / 215,6 \\
& f_{1}=0,3
\end{aligned}
$$

d. Head Loss

1) Head loss pada selang

$$
\begin{aligned}
& h_{L}=f \frac{L}{d} \frac{\mathrm{v}^{2}}{2 g} \\
& =0.3 \frac{1}{6.35 \times 10^{-3}} \frac{(3,43)^{2}}{2(9,8)} \\
& =28,35 \mathrm{~m}
\end{aligned}
$$

2) Head loss pada belokan

a) Head loss pada elbow Diketahui jumlah elbow pada sistem sebanyak 1 dan nilai $K$ untuk belokan $90^{\circ}$ sebesar 0,2 . didapat :

$$
\begin{aligned}
\Delta h_{f} & =K\left(\frac{\mathrm{v}^{2}}{2 g}\right) \\
& =0,2\left(\frac{(3,43)^{2}}{2(9,8)}\right) \\
& =0,12 \mathrm{~m}
\end{aligned}
$$

b) Head loss pada tee

Diketahui jumlah tee pada sistem sebanyak 1 dan nilai $K$ untuk tee sebesar 2,0.

$$
\Delta h_{f}=K_{L} \frac{\mathrm{v}^{2}}{2 g}
$$

$$
\begin{aligned}
& =2,0 \frac{(3,43)^{2}}{2(9,8)} \\
& =1,2 \mathrm{~m}
\end{aligned}
$$

3) Head loss pada filter Diketahui :

$$
\begin{gathered}
\rho=0,902 \mathrm{~kg} / \text { liter } \\
=902 \mathrm{~kg} / \mathrm{m}^{3} \\
Q=8,33 \times 10^{-5} \mathrm{~m}^{3} / \mathrm{s} \\
v=3,43 \mathrm{~m} / \mathrm{s} \\
d_{\text {filter }}=1,27 \times 10^{-2} \mathrm{~m}
\end{gathered}
$$

Maka :

$$
\begin{aligned}
F & =\rho \times Q \times v \\
& =902 \times\left(8,33 \times 10^{-5}\right) \\
& \quad \times 3,43
\end{aligned}
$$

Sehingga nilai $p_{\text {filter }}$ :

$$
\begin{aligned}
p_{\text {filter }} & =\frac{F}{A} \\
& =\frac{0,25}{\frac{1}{4} \pi d^{2}} \\
& =\frac{0,25}{\frac{1}{4} \pi\left(1,27 \times 10^{-2}\right)^{2}} \\
& =1973.5 \mathrm{~Pa} \\
& =201,24 \mathrm{~kg} / \mathrm{ms}^{2}
\end{aligned}
$$

Maka Head loss pada filter adalah :

$$
\begin{aligned}
H & =\frac{p}{\rho g} \\
& =\frac{201,24}{902 \times 9,8} \\
& =0,02 \mathrm{~m}
\end{aligned}
$$

Setelah seluruh head loss diketahui, sehingga jumlah $h l$ total dapat dihitung :

$$
\begin{aligned}
h l & =28,35+0,24+0,2 \\
& =28,79 m
\end{aligned}
$$


Rancang Bangun Oil System untuk Turbocharger Gas Turbine Engine Dengan Inducer Diameter 1,75 Inch

e. Tekanan Total $\left(p_{\text {total }}\right)$

Dari perhitungan, diketahui $H_{\text {total }}=28,79 \mathrm{~m}$, dan density Shell Helix HX3 ( $\rho=$ $902 \mathrm{~kg} / \mathrm{m}^{3}$ ), maka tekanan total dapat diketahui dengan rumus :

$$
\begin{aligned}
p_{\text {total }} & =h l \times \rho \times g \\
& =28,79 \times 902 \times 9,8 \\
& =254492,084 \mathrm{~Pa} \\
& =37 \mathrm{psi}
\end{aligned}
$$

f. Head statis total (ha)

Untuk menghitung besar head statis maka penulis menggunakan head statis maksimum. Diketahui head statis maksimum adalah jarak dari dasar reservoir ke port turbocharger. Maka besar head statis maksimum adalah 0,6 m.

g. Head Tekanan

$\Delta h p$ adalah perbedaan head tekanan yang bekerja pada kedua permukaan air (m) $\Delta h p=$ $h p_{2}-h p_{1}$, karena keduanya sama-sama menggunakan tekanan atmosfer dan dengan perbedaan ketinggian kurang dari $1000 \mathrm{ft}$ maka $\Delta h p$ dapat diabaikan.

h. Head Kecepatan (hk)

Head kecepatan akhir pada aliran fluida adalah :

$$
\begin{aligned}
h k & =\frac{v^{2}}{2 g} \\
& =\frac{(3,43)^{2}}{2 \times 9,8} \\
& =0,6 \mathrm{~m}
\end{aligned}
$$

i. Head Total Pompa

$$
\begin{aligned}
H & =h a+\Delta h p+h l+h k \\
& =0,6+0+28,79+0,6
\end{aligned}
$$

$$
=30 \mathrm{~m}
$$

j. Daya Pompa $(P)$

Setelah head total diketahui, maka daya yang dibutuhkan pompa didapat :

Diketahui :

$$
\begin{aligned}
\rho & =902 \mathrm{~kg} / \mathrm{m}^{3} \\
Q & =8,33 \times 10^{-5} \mathrm{~m}^{3} / \mathrm{s} \\
H & =30 \mathrm{~m} \\
g & =9,8 \mathrm{~m} / \mathrm{s}^{2}
\end{aligned}
$$

Maka :

$$
\begin{aligned}
P= & \rho \times g \times Q \times H \\
= & 902 \times 9,8 \times(8,33 \\
& \left.\times 10^{-5}\right) \times 30 \\
= & 93,87 \text { watt }
\end{aligned}
$$

9. Menghitung Kapasitas Reservoir Perancangan reservoir berdasarkan kebutuhan kapasitas fluida pada sistem.

a. Menghitung Volume Selang

$$
\begin{aligned}
\left(V_{\text {selang }}\right) & \\
V_{\text {selang }} & =L_{\odot} \times t \\
& =\frac{1}{4} \pi d^{2} \times t \\
& =\frac{1}{4} \pi\left(6.35 \times 10^{-3}\right)^{2} \times 1 \\
& =3,16 \times 10^{-5} \mathrm{~m}^{3} \\
& =3,16 \times 10^{-2} \text { liter }
\end{aligned}
$$

b. Menghitung Volume Pump

$$
\begin{aligned}
\left(V_{\text {pump }}\right) & \\
V_{\text {pump }} & =L_{\odot} \times t \\
& =\frac{1}{4} \pi d^{2} \times t \\
& =\frac{1}{4} \pi(0,019)^{2} \times 0,14 \\
& =4 \times 10^{-5} \mathrm{~m}^{3} \\
& =4 \times 10^{-2} \text { liter }
\end{aligned}
$$


c. Menghitung Volume Filter

$\left(V_{\text {filter }}\right)$

$$
\begin{aligned}
V_{\text {filter }} & =L_{\odot} \times t \\
& =\frac{1}{4} \pi d^{2} \times t \\
& =\frac{1}{4} \pi(0,0127)^{2} \times 0,9 \\
& =1,14 \times 10^{-5} \mathrm{~m}^{3} \\
& =1,14 \times 10^{-2} \text { liter }
\end{aligned}
$$

d. Menghitung Volume Return

Line $\left(V_{\text {return line }}\right)$

$V_{\text {return line }}=L_{\odot} \times t$

$$
\begin{aligned}
= & \frac{1}{4} \pi d^{2} \times t \\
= & \frac{1}{4} \pi(0,0127)^{2} \\
& \times 0,5 \\
= & 6,33 \times 10^{-5} \mathrm{~m}^{3} \\
= & 6,33 \times 10^{-2} \text { liter }
\end{aligned}
$$

e. Menghitung

Kapasitas

Reservoir

Kapasitas reservoir adalah 2,5

kali dari kebutuhan oli pada sistem

Diketahui :

$$
\begin{aligned}
\mathrm{V}_{\text {selang }} & =3,16 \times 10^{-2} \text { liter } \\
\mathrm{V}_{\text {pump }} & =4 \times 10^{-2} \text { liter } \\
\mathrm{V}_{\text {filter }}= & 1,14 \times 10^{-2} \text { liter } \\
\mathrm{V}_{\text {return line }}= & 6,33 \times 10^{-2} \text { liter } \\
\mathrm{V}_{\text {selang }}= & 3,16 \times 10^{-2} \\
& +4 \times 10^{-2} \\
& +1,14 \times 10^{-2} \\
& +6,33 \times 10^{-2}
\end{aligned}
$$

$$
=0,2 \text { liter }
$$

Maka Kapasitas reservoir $=2,5 \mathrm{x}$ $0,21=0,52$ liter

Dari ukuran di atas, penulis dapat mencari kapasitas penampung (volume) reservoir yang diinginkan. Perhitungan volume reservoir adalah :

Diketahui :

$\mathrm{r}=$ Jari-jari reservoir $(0,485 \mathrm{dm})$

$\mathrm{t}=$ Tinggi reservoir $(1,5 \mathrm{dm})$

$\pi=$ konstanta reservoir $(3,14$

Maka volume reservoir :

$\mathrm{V}_{\text {reservoir }}=\mathrm{V}_{\text {tabung }}=\pi \mathrm{r}^{2} \mathrm{t}$

$\mathrm{V}_{\text {reservoir }}=3,14 \times(0,48)^{2} \times 1,5$

$\mathrm{V}_{\text {reservoir }}=1,08 \mathrm{dm}^{3}$

\section{Interpretasi Hasil Uji Coba Rancangan}

Setelah dilakukan uji coba rancangan turbocharger gas turbine engine, dapat disimpulkan bahwa perancangan oil system yang penulis rancang berhasil. Oil system dapat bekerja dengan baik sesuai dengan fungsinya, yaitu mengalirkan oli sesuai yang dibutuhkan system yaitu 37 psi untuk menjaga shaft bearing pada turbocharger gas turbine engine tidak overheat dan mengalami keausan, sehingga rancangan turbocharger gas turbine engine dapat bekerja dengan baik dan stabil.. Berikut adalah table interpretasi hasil uji coba rancangan

\begin{tabular}{|c|c|c|c|c|}
\hline No. & Komponen & Kriteria Perancangan & Hasil Uji Coba Rancangan & Keterangan \\
\hline 1. & Reservoir & $\begin{array}{l}\text { Mampu menampung oli } \\
\text { yang dibutuhkan oleh } \\
\text { sistem }\end{array}$ & $\begin{array}{l}\text { Reservoir dengan oli sebanyak I,8 } \\
\text { liter mampu menyuplai oli untuk } \\
\text { pelumasan pada shaft bearing } \\
\text { turbocharger }\end{array}$ & Berhasil \\
\hline 2. & Oil pump & $\begin{array}{l}\text { Mampu mengalirkan oli } \\
\text { dengan tekanan sebesar } \\
37 \text { psi pada rancangan }\end{array}$ & $\begin{array}{l}\text { Oil pump mampu mengalirkan oli } \\
\text { untuk melumasi shaft bearing } \\
\text { yang dibutuhkan dalam } \\
\text { rancangan turbocharger gas }\end{array}$ & Berhasil \\
\hline
\end{tabular}


Rancang Bangun Oil System untuk Turbocharger Gas Turbine Engine Dengan Inducer Diameter 1,75 Inch

\begin{tabular}{|c|c|c|c|c|}
\hline No. & Komponen & Kriteria Perancangan & Hasil Uji Coba Rancangan & Keterangan \\
\hline & & $\begin{array}{l}\text { turbocharger gas turbine } \\
\text { engine }\end{array}$ & $\begin{array}{l}\text { turbine engine sehingga tidak } \\
\text { terjadi overheat. }\end{array}$ & \\
\hline 3. & Oil Filter & $\begin{array}{l}\text { Mampu menghasilkan } \\
\text { aliran oli yang bersih } \\
\text { untuk shaft bearing pada } \\
\text { pada turbocharger }\end{array}$ & $\begin{array}{l}\text { Filter mampu menghasilkan } \\
\text { aliran oli yang bersih pada } \\
\text { rancangan turbocharger gas } \\
\text { turbine engine }\end{array}$ & Berhasil \\
\hline 4. & $\begin{array}{l}\text { Water } \\
\text { Cooling } \\
\text { System }\end{array}$ & $\begin{array}{l}\text { Mampu memberikan } \\
\text { perlindungan pada hose } \\
\text { bearing dengan water } \\
\text { jacket }\end{array}$ & $\begin{array}{l}\text { Water cooling system mampu } \\
\text { mengurangi panas yang terjadi } \\
\text { dengan membawa hawa panas } \\
\text { pada hose bearing. }\end{array}$ & Berhasil \\
\hline 5. & $\begin{array}{l}\text { Pressure } \\
\text { Gauge }\end{array}$ & $\begin{array}{l}\text { Mampu memberikan } \\
\text { informasi tekanan oli } \\
\text { yang mengalir pada } \\
\text { flexible hose }\end{array}$ & $\begin{array}{l}\text { Pressure gauge menunjukkan } \\
\text { tekanan oli sesuai dengan } \\
\text { tekanan oli pada rancangan } \\
\text { turbocharger gas turbine engine }\end{array}$ & Berhasil \\
\hline 6. & $\begin{array}{l}\text { Flexible } \\
\text { Hose }\end{array}$ & $\begin{array}{l}\text { Mampu mengalirkan dan } \\
\text { menahan tekanan oli } \\
\text { yang mengalir pada } \\
\text { selang }\end{array}$ & $\begin{array}{l}\text { Selang mampu mengalirkan dan } \\
\text { menahan tekanan oli yang } \\
\text { mengalir }\end{array}$ & Berhasil \\
\hline 7. & Spark Plug & $\begin{array}{l}\text { 1. Mampu menghasilkan } \\
\text { bunga api } \\
\text { 2. Mampu membakar } \\
\text { bahan bakar di } \\
\text { combustion chamber }\end{array}$ & $\begin{array}{l}\text { 1. spark plug mampu } \\
\text { menghasilkan bunga api } \\
\text { 2. Spark plug mampu membakar } \\
\text { bahan bakar sehingga rancangan } \\
\text { turbocharger dapat menyala }\end{array}$ & Berhasil \\
\hline
\end{tabular}

\section{KESIMPULAN DAN SARAN}

\section{Kesimpulan}

Dari hasil perhitungan dan perancangan yang telah ditentukan pada oil system turbocharger gas turbine engine maka penulis dapat menyimpulkan beberapa hal sebagai berikut :

1. Berdasarkan peritungan perancangan, didapatkan tekanan oli yang dibutuhkan untuk mengalirkan oli pada rancangan turbocharger gas turbine engine sebesar 37 psi.

2. Viskositas oli yang digunakan pada rancangan turbocharger gas turbine engine adalah $0,007 \mathrm{~kg} / \mathrm{ms}$, sehingga penulis memilih SAE 20W-50 sebagai pelumas yang digunakan.

\section{Saran}

1. Karena suhu yang dihasilkan dari pembakaran pada rancangan turbocharger gas turbine engine memiliki suhu yang tinggi, sehingga untuk mengalirkan oli digunakan pipa.

2. Pastikan untuk menyalakan oil system terlebih dahulu agar shaft bearing turbocharger sudah terlapisi dengan pelumas sebelum melakukan percobaan.

\section{Daftar Pustaka}

Crane, D. (1996). Powerplant (T. Michmerhuizen, ed.). Newcastle: Aviation Supplies \& Academics, Inc.

Giles, R. V., \& Sumitro, H. W. (1984). Mekanika Fluida \& Hidraulika. Penerbit Erlangga.

Hashem, A., Mohamed, A., Magdy, A., Saman, A., Mahmoud, H., Abdelsalam, O., ... Aboelabas, Y. (n.d.). Design and Manufacturing of a Turbocharger Jet Engine.

J.K.Gupta, R. S. K. A. (2005). Textbook of Machine Design 14th edition. 
Langit Biru: Jurnal Ilmiah Aviasi Vol. 14 No. 1 Februari 2021

ISSN (p) 1979-1534 ISSN (e) 2745-8695

EURASIA PUBLISHING

HOUSE (PVT.) LTD.

Murwanto, A. D. (2014). Pemanfaatan

Gas Buang Hasil Pembakaran

Untuk Induksi Paksa Langkah

Hisap Motor Diesel: Sistem Turbocharger.

Pirro, D. ., \& Wessol, A. . (1980). Lubrication Fundamental (First). Retrieved from http://www.dekker.com

Polichronis, D., Evaggelos, R., Alcibiades, G., Elias, G., \& Apostolos, P. (2013). Turbocharger Lubrication Lubricant Behavior and Factors That Cause Turbocharger Failure / Turboşarj Yağlama - Yağlama Davranışı ve Turboşarj Arızasına Neden Olan Faktörler. International Journal of Automotive Engineering and Technologies, 2(1), 40-54-54. https://doi.org/10.18245/ijaet.09 503

Schobeiri, M. T. (2018). Gas Turbine Design, Components and System Design Integration (First). https://doi.org/10.1007/978-3319-58378-5

Shigley, J.E. (1972). Mechanical engineering design. 2.ed (tenth). New York: McGraw-Hill Education.

Shigley, Joseph E., Mischke, C. R., \& Jr., T. H. B. (2004). STANDARD HANDBOOK OF MACHINE $D E S I G N$ (Third). New York: The McGraw-Hill Companies.

WHITTLE, F. (1981). Aircraft Propulsion General. In Gas Turbine Aero-Thermodynamics (pp. 145-152). https://doi.org/10.1016/b978-008-026718-0.50018-5

Young, H. D. (1992). Fisika Universitas, Jilid.

http://blog.parker.com/three-keywords-in-hydraulic-hose-sizingid-dash-size-and-nomogram

https://gcg.com.au/component/rstickets pro/view-article/18-watercooled-turbos-they-need-water 